\title{
REGADÍO Y TRANSFORMACIÓN DE LOS ESPACIOS JURISDICCIONALES EN EL BAJO SEGURA DURANTE LA ÉPOCA FORAL MODERNA
}

\author{
David Bernabé Gil \\ Universidad de Alicante ${ }^{1}$
}

\section{RESUMEN}

Se analiza en este trabajo las transformaciones operadas en la articulación territorial de la jurisdicción de aguas en un macrosistema hidráulico complejo, controlado inicialmente por la ciudad de Orihuela - en el sur valenciano-, a lo largo de los siglos XVI y XVII. Su dinámica temporal muestra, por un lado, una dispersión desigual de las instancias de gestión interna correspondientes a los diferentes sistemas de acequias, que aparece ligada a los procesos de segregación municipal operados en el antiguo término general de dicha ciudad y a la construcción de nuevos azudes. Por otro, se asiste también, para contrarrestar aquella tendencia centrífuga, al reforzamiento de una jurisdicción de aguas centralizada, con la importante novedad que supuso su control directo por parte de la Corona.

Palabras clave: Regadío, jurisdicción de aguas, Bajo Segura, siglo XVI, siglo XVII.

\section{ABSTRACT}

In this essay we analyze the changes that occurred in the water jurisdiction within an hydraulic complex macrosystem, controlled in the beginning by the city of Orihuela - in the South of the Valencian region (Spain) - throughout the XVI ${ }^{\text {th }}$ and XVII ${ }^{\text {th }}$ centuries. As a result, we will show, on the one hand, an unequal dispersion of the instances of internal management corresponding to the different systems of irrigation ditches, which is connected to the process of municipal segregation produced in the ancient general district of the city of Orihuela and the building of new dams. On the other hand, we will pay attention to the reinforcement of a centralized water jurisdiction, with the important innovation that supposed a direct control by the Crown.

Key words: Irrigation, water jurisdiction, Bajo Segura (Alicante), 16 and 17 th century.

1 Este trabajo ha sido realizado en el marco del Proyecto de Investigación HAR2011-27062, financiado por el Ministerio de Ciencia e Innovación. 
En íntima vinculación con las cambiantes vicisitudes históricas, la organización del territorio ha experimentado a lo largo del tiempo transformaciones no siempre atribuibles a supuestas directrices procedentes de los correspondientes centros de emanación del poder. Los resultados - inacabados - de esas mutaciones operadas en la ordenación del espacio remiten con frecuencia a la acción combinada de iniciativas surgidas en contextos históricos precisos para tratar de optimizar el aprovechamiento de los recursos - de todo tipo- disponibles, por un lado, y de los condicionantes impuestos por el marco geográfico, pero también institucional, social, económico y cultural en que aquéllas han de desenvolverse, por otro. Avanzar en el conocimiento de la configuración del territorio implica, por tanto, atender no solamente a los fundamentos estructurales que han condicionado su devenir, sino, sobre todo, a los procesos de cambio que se han ido sucediendo a lo largo del tiempo; esto es, a la dinámica histórica, entendida en toda su complejidad, resultante de la interrelación entre las múltiples vertientes que la integran. Y, de entre las diversas perspectivas desde las que es posible contemplar la organización histórica del territorio, no es quizás la menos relevante la que incide en sus aspectos jurídico-institucionales; pues, a fin de cuentas, constituyen buena parte de los fundamentos sobre los que se levantan otras miradas, como pueden ser, por ejemplo, las que se proyectan sobre el paisaje.

A partir de estas consideraciones elementales, se propone en este trabajo una aproximación a la dinámica experimentada por la articulación interna de un territorio concreto, dotado de una personalidad estructural, a lo largo de un periodo temporal suficientemente prolongado como para poder apreciar la incidencia de posibles elementos de cambio. Pero más que atender a la pluralidad de variables significativas previsiblemente involucradas en la determinación de los procesos que se trata de aprehender, se ha optado por reducir el campo de observación para centrarnos en las interrelaciones generadas entre algunas de aquéllas, que, a juzgar por los indicios disponibles, parecen mostrar gran capacidad explicativa. Concretamente, se trata de analizar las transformaciones operadas en la articulación interna de las instancias jurisdiccionales, con proyección sobre sus correspondientes demarcaciones espaciales, en la actual comarca del Bajo Segura, a partir de las interconexiones establecidas con uno de los elementos distintivos que marcaron su devenir histórico, al menos durante el período objeto de observación - la época foral moderna-, cual fue la organización del regadío.

\section{PRECEDENTES MEDIEVALES}

La actual comarca del Bajo Segura - aun con la imprecisión que aqueja a dicho concepto districtual - coincide, a grandes rasgos, con el alfoz o término general asignado tras la conquista cristiana a la entonces villa de Orihuela; lo que confiere al territorio en cuestión una personalidad histórica bien definida, a salvo de cualquier otra fórmula de reordenación espacial más o menos artificiosa o convencional. Y esta continuidad a lo largo de los siglos seguramente no ha sido ajena, precisamente, a la importancia que, incluso desde tiempos anteriores a los que aquí tratamos, asumió el regadío, no solamente como operativo mecanismo de aprovechamiento de los recursos naturales, sino también - por lo que aquí interesa - como aglutinador de una serie de rasgos institucionales e incluso socioculturales susceptibles de configurar una determinada relación con el medio.

A través de una serie de azudes, acequias y azarbes, el líquido, escaso y, por ello, valioso elemento que discurría por el cauce del Segura fructificaba, una vez traspasada la frontera del reino de Valencia, un amplio perímetro de irrigación que, en los albores de la modernidad, posiblemente se aproximara ya bastante a las 10.000 hectáreas de superficie, sin contar los 
fluctuantes almarjales que delimitaban algunos de sus contornos ${ }^{2}$. Este inmenso macrosistema hidráulico - uno de los más extensos, por entonces, de todo el levante peninsular - no habría de permanecer invariable con el transcurso de los siglos; como tampoco lo hizo la articulación interna de los núcleos de poblamiento - con sus correspondientes instancias jurisdiccionales - insertos en el término general de Orihuela.

Por lo que se refiere a esta última cuestión, en vísperas de la construcción de la monarquía hispánica por los Reyes Católicos, cabe inventariar un total de tres aldeas o lugares dependientes de la ciudad de Orihuela - Callosa, Almoradí y Catral-, dos señoríos de jurisdicción baronal - Albatera y Daya Nueva - y varias alquerías cuyos titulares probablemente estuvieran en condiciones de reclamar, como mucho, la simple jurisdicción civil. A todo ello habría que añadir la otrora villa realenga de Guardamar, que había perdido su antigua condición de núcleo real independiente, pues desde hacía siglo y medio se hallaba vinculada a la ciudad por ciertos lazos de dependencia jurisdiccional, aunque mantenía su tradicional autonomía en materia administrativa, a diferencia de las tres aldeas mencionadas, que eran gobernadas por meros lugartenientes - o delegados - de los oficiales oriolanos. $\mathrm{Al}$ margen de este caso especial, en una valoración apresurada cabría precisar que únicamente las dos baronías citadas podían considerarse de facto verdaderas entidades municipales, sin perjuicio de los derechos que continuaba manteniendo la ciudad de Orihuela en determinadas materias, como la mancomunidad de los pastos y amprius, alguna contribución fiscal de escasa entidad, el avituallamiento triguero o, precisamente, la jurisdicción sobre las aguas de riego (Bernabé, 1993a).

En efecto, en virtud de un antiguo privilegio otorgado por el rey Alfonso X de Castilla en 1275, vigente a lo largo de toda la época foral, la jurisdicción en materia de riegos sobre toda la huerta comprendida en el término general de Orihuela fue encomendada al sobrecequiero de la villa. Con la creación de este oficio, a su primer ocupante, Pedro Zapatero, se asignaron las atribuciones y competencias correspondientes. Debía encargarse, entre otras materias, de vigilar el mantenimiento de la red de acequias, disponiendo su limpieza o monda anual, de repartir las aguas con equidad y hacer guardar los turnos y modo de regar «por las paradas do solían tomar su tanda en tiempo de moros e non por otro lugar», y de ejercer la jurisdicción, resolviendo las denuncias y contenciosos producidos y aplicando las penas señaladas, con la asistencia, en caso necesario, de las autoridades municipales. Concretamente, se disponía que

«el Sobresequiero haya los pleytos de las aguas e de las otras cosas que pertenecen al su oficio en todos dias feriados o no feriados....e todas las otras cosas que acaescan que no son en esta carta mando que el Sobresequiero las libre con consejo de homes buenos.....E mando a vos el Consejo, Alcaldes e Alguasil e Jurados que cada ves que Pedro Çapatero vos huviere menester e vos demandare para cumplir esto que yo mando le ayudedes».

En cuanto al ámbito territorial sujeto a su dominio, quedaba claro que se extendía por todo el correspondiente a «las Acequias e los Azarbes....las aguas de Orihuela e de su termino». Pero también se contemplaba la designación por el Sobrecequiero de oficiales subalternos para el cuidado de las diversas acequias: «los Acequieros que vos impusieredes» (Llorens, 2001: 254-255). Finalmente, y aunque no se especifique en el documento, el nombramiento de Zapatero debió tener duración indefinida; circunstancia que ya no concurre

2 El primer padrón de regantes conocido para toda la huerta, realizado en 1535, contabiliza un total de 11.604 hectáreas (Bernabé, 1999:192) 
en los sobrecequieros que le siguieron desde que, a partir de 1295, el Infante D. Fernando concedió la periodicidad anual de dicho cargo, a petición de Orihuela (Barrio 1993: 122). Con ello, quedaba reforzada su vinculación funcional con la instancia municipal, como ámbito electoral y de control institucional.

Al corresponder a una etapa inmediata a la conquista, en que la Corona trataba de afianzar la institución municipal en el realengo, dotando a las más importantes entidades vecinales de un poderoso régimen local, la jurisdicción sobre las aguas se contempló como una parcela más del espacio político municipal. La pronta incorporación del término oriolano al reino de Valencia, en 1304, no parece que acarreara novedades importantes en lo que al perfil institucional del sobrecequiero se refiere, por mucho que a partir de entonces el territorio tuviera que regirse por los fueros valencianos (Del Estal, 1982). El teórico dominio eminente que los fueros reservan a la Corona sobre las aguas corrientes del reino, como bienes de uso público, no fue un obstáculo para la continuidad de la jurisdicción de aguas como un espacio de poder «cedido» a la institución municipal; tal como se observa también en otros ámbitos valencianos que nunca llegaron a estar bajo soberanía castellana. Salvo casos excepcionales, en que una activa e interesada participación de la Corona en la configuración del sistema hidráulico justificó la asunción de un mayor protagonismo en su control institucional - la Acequia Real del Júcar, por ejemplo-, la jurisdicción de aguas en el realengo valenciano se dejó en manos de las instancias municipales, desde el convencimiento de que era en esa escala local, inmediata y fácilmente asequible al usuario, donde su funcionamiento podía resultar más operativo. Por otro lado, al regirse la administración del riego por costumbres locales, en gran parte heredadas de época musulmana - como explícitamente se indicaba en muchos casos - , y ante la conveniencia de conseguir sintonizar el ejercicio jurisdiccional con las prácticas consensuadas por los regantes - habitualmente organizados en comunidades - para el óptimo aprovechamiento de los recursos hídricos, la jurisdicción de aguas y el derecho subsiguiente fueron adquiriendo una fisonomía propia y hasta cierto punto independiente que acabó por conferirles un carácter privativo (Glick, 1988; Romero-Peris, 1992).

La unidad y centralidad de la jurisdicción de aguas se justificaba, en gran medida, por la complejidad y relativa interdependencia de las redes de irrigación-avenamiento y la necesidad de mantener los equilibrios internos en el macrosistema hidráulico que conformaba toda la huerta de Orihuela, para su óptimo funcionamiento. La concentración de la jurisdicción de aguas en época medieval tenía su correlato en la ubicación - asimismo centralizada - de los azudes y, en consecuencia, de las boqueras de las acequias que distribuían el agua a lo largo y ancho de la huerta del Segura. Así, con la excepción del azud de Rojales, que abastecía las acequias que irrigaban el término de Guardamar, todos los acueductos que discurrían por las poblaciones antes mencionadas tenían su origen en el término particular de la ciudad de Orihuela, siendo tributarios de los azudes de las Norias - junto a la frontera murciana-, de la acequia de los Huertos y los denominados de Callosa y Almoradí - ya en los intramuros de Orihuela. A partir de ellos se fueron configurando sistemas de acequias de diversa complejidad que, a lo largo del tiempo, habrían de experimentar una dinámica dispar, tanto en su estructura territorial, como - en lo que aquí más interesa - en su vertiente jurisdiccional ${ }^{3}$. Además de las modificaciones concernientes a la organización reticular interna del sistema de irrigación y drenaje, que acabaron afectando, en mayor o menor medida, a la práctica totalidad de las nueve acequias tributarias de los cuatro azudes oriolanos, también se ha podido detectar, en efecto, la presencia de determinados elementos

3 Los nombres de las acequias son los siguientes: Puerta de Murcia, Alquibla, Moquita, Molina, Huertos, Escorratell, Callosa, Almoravit y Almoradí (Cavanilles, 1798; Roca de Togores, 1832). 
de cambio que incidieron en la articulación de la jurisdicción de aguas a lo largo de la época foral moderna

\section{DISGREGACIÓN JURISDICCIONAL EN EL MESOSISTEMA DE LA ACEQUIA DE CALLOSA}

Cronológicamente, fue en el territorio irrigado por la acequia de Callosa donde se produjeron las primeras mutaciones de relieve. A fines del medievo, dicha acequia, cuya boquera se ubicaba intramuros de la ciudad de Orihuela, debía regar primeramente unas 4.000 tahúllas en dicho término, antes de abastecer también a un pequeño sector de la alquería de Redován - cuya principal fuente de aprovisionamiento hídrico procedía, no obstante, de la acequia de Escorratell. Se adentraba a continuación en el diezmario de la aldea realenga de Callosa, donde beneficiaba cerca de 15.000 tahúllas, al tiempo que se dividía en dos ramales: el de la izquierda discurría por dos extensos dominios nobiliarios y finalizaba en la baronía de Albatera; el de la derecha continuaba por tierras de Callosa hasta atravesar por completo el diezmario realengo de Catral, integrado por unas 10.000 tahúllas ${ }^{4}$. En la etapa que marca el tránsito del medievo a la modernidad emergieron tres señoríos alfonsinos en la zona de riegos tributaria de dicha acequia, en virtud de las correspondientes cartas de población otorgadas por entonces a vasallos que seguramente ya venían cultivando parte de esas mismas tierras mediante otras fórmulas contractuales más precarias que la enfiteusis ${ }^{5}$. Se trata de la formalización de las colonizaciones señoriales de Redovan - en 1491 - , Cox — en 1483 - y La Granja — antes de 1490 - que, en total, acumulaban cerca de 3.000 tahúllas de riego (Bernabé, 1992).

Con la consolidación de estos tres dominios señoriales y su correspondiente reconversión en entidades municipales con jurisdicción de mixto imperio, los asuntos internos de aguas concernientes a los vasallos, a sus tenencias - o establecimientos enfiteuticos - y a las constitutivas de la reserva señorial pasarán a depender de la jurisdicción señorial, ejercida mediante procurador o - como fue más frecuente - a través del oficio de sobrecequiero o cequiero local $^{6}$. En algún caso, incluso llegaron a elaborarse ordenanzas de riego de uso interno, como las que en 1626 dispuso y dió a la imprenta el señor de Cox, que consagraba el reparto de las tandas entre las distintas paradas, con indicación de las penas - de 60 sueldos y 8 días de cárcel- previstas para los infractores, y una mención a los poderes otorgados, en cuya virtud se ordenaba «al Sobrecequiero que agora es y por tiempo será, que guarde y haga guardar las ordenanzas sobredichas; y a quien contraviniere a ellas execute en las penas sobredichas» ${ }^{7}$. La emergencia de una entidad señorial conllevaba, por tanto, una merma de la jurisdicción del sobrecequiero de la ciudad de Orihuela, al menos en su capacidad para intervenir dentro del territorio constitutivo de aquél. Se propiciaba, así, un proceso de disgregación territorial que no dejaba de afectar a la jurisdicción de aguas, aunque sus consecuencias prácticas en esta

4 Las cifras relativas a las tahúllas irrigadas en cada diezmario proceden de los datos que ofrece el padrón de regantes de 1535, mediante aproximación al millar, por defecto. Han de tomarse, por tanto, como meramente indicativas. AMO: $N^{o}$ 1.248. Elaboración propia. La tahúlla de Orihuela equivale a 1.185 metros cuadrados; de modo que una hectárea equivale a 8,4 tahúllas.

5 Sobre la naturaleza, significado y alcance de la jurisdicción alfonsina, como vía generadora de municipios, con especial referencia a la zona que nos ocupa, vid. fundamentalmente Pla (1995), Gil Olcina (1988, 1999), Bernabé (1993a).

6 Se detecta la presencia de sobrecequieros señoriales en Albatera, Redován y Cox. AMO: Sobrecequiero. $N^{o} 70,28,56 v ;$ Sobrecequiero. $N^{o} 72$, ff. 90, 135; Sobrecequiero. $N^{o} 76$, f. 111.

7 Orden que se ha de guardar en regar la huerta de Cox, en los días de su tanda: hecha por don Juan Royz, Señor de dicho Lugar, Imp. en Orihuela, por Juan Vicente Franco, 1626, 2 pp. 
materia resultaran limitadas por la exigencia de mantener unificado algún tipo de control sobre el mesosistema de la acequía (Bernabé, 1993a).

Una de las situaciones más frecuentes, que evidenciaba la jerarquía de poderes resultante, se planteaba cuando las partes contendientes en un conflicto de aguas pertenecían a entidades poblacionales distintas. Como el alcance de la jurisdicción señorial no podía sobrepasar los límites territoriales de su dominio, ni podía afectar al reo que no le estaba sometido a vasallaje, en tales casos se discutía si el conocimiento de la causa debía corresponder en primera instancia al sobrecequiero de Orihuela o al señor del reo. Y, curiosamente, las posiciones mantenidas en esta disputa no dependían de la categoría jurisdiccional alcanzada por el señor del lugar, sino de su concreta situación respecto al riego. Así, en los hurtos de agua - y demás acciones delictivas - perpetrados por vasallos de señoríos ubicados aguas arriba contra los avecindados aguas abajo, estos últimos señalaban al oficial de la ciudad como juez competente, ante la lógica desconfianza que depositaban en la difícil imparcialidad del sobrecequiero señorial ajeno. Por el contrario, los vasallos ubicados aguas arriba defendían la jurisdicción de sus correspondientes señores, ya que habitualmente eran ellos quienes habían cometido la infracción y buscaban protección. Y, en efecto, son varias, a este respecto, las denuncias que se conservan en los registros del sobrecequiero oriolano - a finales del siglo XVI - en las que figura como actor un vasallo de un señorío jussà - Albatera - acusando a otro subirà - Cox y la Granja, por este orden ${ }^{8}$. La supremacía del juez urbano quedó reconocida, asimismo, en 1548, cuando comparecieron ante su presencia los procuradores de los señores de Albatera, La Granja y Cox, para someterse a su dictamen, al haber solicitado el primero un incremento de las penas por hurtos de aguas, pues los tradicionales 5 sueldos por infracción resultaban una cuantía ridícula, de escasa capacidad disuasoria. Haciendo uso de sus atribuciones, el sobrecequiero de Orihuela las elevó a 30 sueldos de día y 60 de noche9.

Mas no siempre los señores - particularmente el de Cox - aceptaron esta situación de subordinación, que, en la práctica, limitaba su jurisdicción de aguas a la ejercida internamente entre sus vasallos. En 1617 acudió aquél ante el Consejo de Aragón para oponerse a las pretensiones del de Albatera, que reclamaba la intervención del sobrecequiero oriolano como juez competente en las denuncias de un señorío a otro. Calificaba concretamente el de Cox tal presunción como «contrafuero, porque ninguno puede ser defraudado sacando de su natural a pleitear fuera de su tierra y también es contra la costumbre que se ha guardado de más de cien años a esta parte, que ha sido poner dichos quexos de agua ante el sobrecequiero del lugar donde se haze el daño» ${ }^{10}$. La posición al respecto mantenida por la ciudad de Orihuela, por su parte, no podía ser más contundente; e interesa reproducir un fragmento porque recoge todos los argumentos posibles que fundamentaban la jurisdicción del sobrecequiero urbano. Tras lamentarse por la sentencia dictada recientemente por el Gobernador, favorable al de Cox - que acabaría provocando el mencionado recurso ante el Consejo, al no conformarse el señor de Albatera ni el síndico de la ciudad-, señalaban las autoridades municipales

«no haver conegut may de tals lo sobrecequier de Coix dels de Albatera, ni lo sobrecequier de Albatera dels de Coix, si tan solament lo sobrecequier de Oriola, per dos rahons: la primera, per que sols esta ciutat té priviletgi per a tenir sobrecequier de aquella y de tot son terme y no les dits pobles, que son

8 AMO: Sobrecequiero, $N^{o} 70$, ff. 27-28, 56v, 60v-62; Sobrecequiero $N^{o} 72$, ff. 14-14v, 75-78; 90; Sobrecequiero 1532-1657, ff. 109-138; entre otros.

9 AMO: Sobrecequiero, $N^{\circ} 76$, ff. $121 \mathrm{v}-127$.

10 ACA: CA: Leg. 867, doc. 18. 
carrers de esta ciutat, y l'altra per que los señors de dits llochs, per tenir sols la jurisdicció alfonsina, sols tenen jurisdicció inter suos y no la tenen per a coneixer dels vasalls de altres señors y també perquè tots los habitants en dits pobles estan subjectes al sobrecequier d'esta ciutat en materia de aygües, per ser tots sos vehins y pendre aygua per a regar dins lo terme d'esta ciutat, per ser sos carrers» ${ }^{11}$.

Por sentencia de la Audiencia de Valencia, publicada el 29 de mayo de 1618, que recogía y aplicaba esta doctrina ${ }^{12}$, quedó definitivamente zanjado el asunto, al tiempo que se marcaba la pauta a seguir - a priori- de cara a las nuevas colonizaciones alfonsinas que se estaban llevando a cabo en el término oriolano y que, sobre todo, habrían de multiplicarse más aun en el futuro. La disgregación territorial que esta vía representaba no podía dejar de afectar a la jurisdicción de aguas, como una manifestación más de la administración municipal. Pero su alcance efectivo no parece que llegara a ser tan acusado en esta materia como en otras derivadas de aquellas segregaciones, ya que reservaba un mayor grado de control al sobrecequiero de la ciudad en relación con el que retuvieron otras magistraturas urbanas. Los sobrecequieros de los señoríos alfonsinos podían intervenir en los asuntos internos suscitados entre los vasallos dentro del término señorial correspondiente durante los días en que tenían asignada la tanda - o turno de riego-; pero carecían de capacidad para actuar en el tiempo restante y en materias que afectaban a los demás regantes de la misma acequia.

Curiosamente, la dinámica jurisdiccional experimentada en los territorios realengos irrigados por la misma acequia de Callosa habría de ser algo distinta. Las aldeas de Callosa y de Catral contaban tradicionalmente con sendos lugartenientes de sobrecequiero, como delegados del de Orihuela, para atender los asuntos de riegos en sus correspondientes diezmarios, durante sus tandas respectivas ${ }^{13}$. Como, por otro lado, además de su condición de lugares dependientes - o carrers - , en ambas zonas una parte considerable de la huerta estaba en manos de propietarios oriolanos, consiguió mantenerse una secular continuidad territorial y jurisdiccional - no exenta de los sempiternos e inevitables conflictos entre regantes jussans y subirans - entre la ciudad y sus aldeas. Así, ante la creciente demanda de agua generada en la zona de Catral - última en regar- como consecuencia del crecimiento agrario que se estaba produciendo, en 1550 el consistorio oriolano autorizó - a petición de los habitantes de esta aldea - la apertura de una nueva acequia que debía tomar agua río abajo para conducirla directamente hasta su territorio ${ }^{14}$. El proyecto no llegó a cuajar — seguramente por su elevado coste o por la oposición de los propietarios de las tierras que el nuevo acueducto debía atravesar-; de modo que aquéllos tuvieron que conformarse con realizar obras de alzado en la pared del azud y una monda en profundidad en la boquera y el lecho para incrementar el caudal de la acequia, que contó con la aprobación del pleno de la comunidad de regantes ${ }^{15}$. Pero la

11 AMO: Contestador de 1617, ff. 437-438

12 Copia de dicha sentencia en ACA: CA: leg. 659, doc. 77/2.

13 La acequia de Callosa se dividía en tres zonas y tandas, con sus correspondientes síndicos, además de los señoríos: la de Orihuela, con 4 días de riego; la de Callosa, con 12; y la de Catral, con 4, hasta 1589, en que se incrementó a 8. Una porción de Redován regaba de la tanda de Orihuela; y los señoríos de Cox, La Granja y Albatera, de la tanda de Callosa. Cada señorío tenía también sus propio síndico y sobrecequiero. ARV: Real Audiencia. Procesos de Madrid, S/173; y Procesos, parte $2^{a}$, S/655

14 AMO: Contestador de 1550, ff. 247-248v

15 AMO: Sobresequier, 1532-1657,ff. 315-329. El coste de las obras ascendió a 653 libras; bastante menos de lo que hubiera ocasionado la apertura de una nueva acequia, teniendo en cuenta la distancia entre Catral y la zona intermedia entre Benejúzar y Alfaytamí, donde se pensaba ubicar inicialmente la boquera. 
aparente armonía no tardaría mucho tiempo en resquebrajarse de forma definitiva; y no precisamente a instancias de los de Catral.

Durante el tercer cuarto de la centuria menudean las noticias sobre conflictos de aguas sustanciados ante el sobrecequiero oriolano en los que figuran implicados regantes de Callosa, bien a título particular, bien como agrupación comunitaria de la tanda correspondiente ${ }^{16}$. Posiblemente no haya que ver en ello novedad apreciable; pero en 1579 los habitantes de dicha aldea dieron un paso decisivo al negociar con la Corona la segregación municipal mediante la obtención del título de universidad, que comportaba la adquisición de una jurisdicción y una administración consistorial propias e independientes (Bernabé, 1988; Navarro, 2001). Las previsibles consecuencias, en materia de riegos, de esa desmembración no pasaron inadvertidas para las autoridades oriolanas, que, en el ítem 14 de su alegación contraria a tal pretensión, señalaban la diferencia que podía generarse con respecto a la situación de los núcleos señoriales, considerados a estos efectos como meras aldeas dependientes:

"Que Catral, Albatera, Coix y La Granja són aldees de la present ciutat y es reguen de dita cèquia y són les últimes en lo regar, y prenent los del lloch de Callosa l'aygua ab que reguen los dels dits llochs, com moltes vegades ho an fet y fan cascun dia, si lo dit lloch de Callosa fos dividit e separat de la present ciutat, los vehins de Oriola haurien de fundar juhí davant los de Callosa, y per dita rahó se siguirien molts grans escàndols y les dites aldees y habitadors en aquelles serien en gran manera molestats de despesses y en altres maneres per los pretessos officials de Callosa, en gran deservey de Sa Magestat y desasosech de dites aldees y de la present ciutat»(Navarro, 2001: 77).

El asunto podía agravarse, además, porque — tal como se afirmaba en otro memorial«el dicho lugar de Callosa no tiene término ninguno, si como a calle que es de Orihuela tiene con los vecinos de la dicha ciudad entremescladas y revueltas las tierras que poseen, y es de manera que los vecinos de dicha ciudad tienen sus tierras y heredades hasta las mismas paredes y casas del dicho lugar» (Navarro, 2001: 81). Seguramente exageraba en sus apreciaciones el síndico de la ciudad; pero en el correspondiente proceso de amojonamiento que sucedió a la segregación, en 1582, aquel planteó recurso formal porque se habían adjudicado al término de Callosa «trenta y set heretats de la horta de la dita ciutat, les més principals que dita ciutat té, les quals estan en lo millor de dita horta, de cavallers, y ciutadans y altres persones honrrades que vihuen y habiten y tenen ses casses $y$ habitations en la dita ciutat de Oriola» (Navarro, 2001: 160). En tales condiciones, la creación de un sobrecequiero propio para Callosa cobraba una especial significación, pues su jurisdicción, además de extenderse sobre el riego de estas haciendas, habría de erosionar inevitablemente la autoridad del oriolano, contribuyendo a desmantelar un importante elemento de control sobre el mesosistema de la acequia.

El privilegio de universidad de Callosa, sin embargo, no mencionaba este oficio entre las magistraturas con que se dotaba a la nueva entidad municipal. Posiblemente la razón de esta omisión haya que buscarla en la naturaleza del formulario adoptado como modelo para este tipo de privilegios, que, al ser único y común para todas las universidades del reino - a diferencia de los títulos de villazgo-, ignoraba las peculiaridades locales (Bernabé, 1988). Pero los callosinos detectaron inmediatamente esta ausencia y consiguieron una provisión complementaria de la Audiencia para poder elegir cada año un sobrecequiero

16 AMO: Contestador de 1558, f. 348; $N^{o} 2.210$, ff. 244-246; $\mathrm{N}^{\circ} 2.225$, ff. 42-53; $N^{o} 2.227$, ff. 214-218; $N^{o} 2.228$, ff. 59-120 $N^{o} 2.229$, ff. 2-5, $N^{o} 2.232$, ff. 19-24; 25-36; 223-237; 444-450. 
propio e independiente ${ }^{17}$. En la ceremonia de toma de posesión de los nuevos oficiales municipales que tuvo lugar en Callosa el 2 de enero de 1580 también se produjo, por tanto, el juramento del sobrecequiero —en la persona de Guillem Pérez (Navarro, 2001: 122). Dos años más tarde, el consell oriolano atribuía a dicha provisión de la Audiencia la «total ruhina e destructió de la dita ciutat y los inconvenientes que se han vist e vehuen a ull»; y encomendaba al embajador nombrado para acudir ante el Consejo de Aragón «supplique a Sa Magt. mane revocar la dita facultat que tenen los de Callosa de elegir sobrecequier y que los de Callosa se hajen de estar en dit cas a la ordenació del sobrecequier de la dita ciutat e del lloctinent que fora en dita Callosa com a costumat» ${ }^{18}$. Todavía en 1584 continuaban las gestiones ante los tribunales regios para impedir que Callosa tuviera sobrecequiero propio ${ }^{19}$. Pero la petición llegaba demasiado tarde para poder prosperar, pues ese mismo año la concesión del privilegio de insaculación a dicha universidad regulaba, en su capítulo 10, la forma de elección del oficio objeto de disputa (Bernabé, 2011b, 188).

Las colisiones entre ambos sobrecequieros, en su mayor parte relacionadas con los supuestos perjuicios ocasionados a los regantes de Catral, no escasearon, en efecto, en los años siguientes ${ }^{20}$. Y, en 1628, obligaron a pronunciarse a la Audiencia de Valencia, que dictaminó a favor de Callosa, al declarar que su sobrecequiero debía conocer «dels clams possats no sols contra los vehins de aquella, però també contra los forasters per rahó de qualsevol contravenció o delicte comés dins lo terme de Callosa en respecte de l'aygua» ${ }^{21}$. Quedaba en evidencia, de este modo, el diferente tratamiento dispensado a la universidad realenga de Callosa, en comparación con el recibido, solo una década antes, por los señoríos de Cox y de La Granja.

Posiblemente para salvaguardar sus posiciones frente a previsibles declaraciones de esta naturaleza - entre otras motivaciones - , la aldea de Catral había tratado también de obtener privilegio de universidad separada en 1584, 1599 y 1604, siguiendo la tendencia que se estaba difundiendo por gran parte del realengo valenciano. En este caso, empero, la tentativa resultó frustrada; tanto por la oposición desplegada por la ciudad de Orihuela en tanto que municipio matriz - algo habitual en este tipo de intentonas - , cuanto por la incapacidad financiera de los habitantes del lugar para sufragar los elevados costes de la segregación. En la primera tentativa, ensayada en 1584, el Consejo de Aragón desestimó la pretensión, ante la contundencia de los argumentos expuestos por el síndico oriolano, que destacó el doble perjuicio que la segregación ocasionaría a la ciudad y a los propios habitantes del lugar; de modo que

«sería total ruyna y acabar de desautoriçar a la dicha ciudad, dexándola sola y sin aldea alguna, y a los vecinos del dicho lugar les es dañoso a causa que nenguno tiene bienes rayzes, ni el propio lugar propios algunos, y si alguna cantidad de dineros tomasen a censal no tendrán sobre qué cargarlos y no podrán pagar los intereses y les sería forzoso haver de despoblar el lugar y hirse dell» ${ }^{22}$.

Aunque las interesadas apreciaciones resultaban un tanto exageradas, la segunda intentona, desarrollada entre 1599 y 1604, fracasó finalmente por no estar dispuestos los de

17 AMO: Contestador de 1582, f. 265.

18 Ibídem, ff. 268-268v

19 AMO: Cartas de 1583-84, ff. 156v.

20 AMO: Sobrecequiero, $N^{\circ} 72$, ff. 113-114

21 TAGELL, L: Epitome Sententiarum Sacre Regie Audientiae Vaentine, manuscrito conservado en la B.U.V, let. C, $n^{\circ}$ 1.087. Copia del texto original de la sentencia, en latin, en ACA: CA: Leg. 892, doc. 123/2

22 AMO: Cartas de 1583-84, ff. 283, 300v. 
Catral a aprontar las 4.000 libras que exigía la Corona a cambio del privilegio (Bernabé, 1988: 16). Más éxito tuvo, en cambio, la iniciativa emprendida por Almoradí solo unos pocos años atrás, que culminó una operación de desmembración jurisdiccional iniciada precisamente en el terreno hidráulico.

\section{EMERGENCIA DE UN NUEVO MACROSISTEMA: EL AZUD DE ALFAYTAMÍ}

No menos complejidad que el sistema de la acequia de Callosa presentaba, a principios de la edad moderna, el correspondiente a la acequia de Almoradí, cuya boquera también se hallaba intramuros de la ciudad, en la margen izquierda del río. Tras unos 7 kilómetros de recorrido por territorio oriolano, una bifurcación por la izquierda daba origen a la arroba de San Bartolomé, mientras que el cauce principal proseguía para ramificarse en las proximidades del precario azud - de estacada y tierra - del molino de Alfaytamí, levantado en el río Segura. El ramal principal lo constituía la entonces denominada acequia de Almoradí y La Daya, que atravesaba ambos territorios, antes de desaguar en los almarjales. Se trataba el primero de ellos de una aldea realenga de Orihuela, cuyas 14.000 tahúllas - aproximadamente - se beneficiaban también de los aportes de otros ramales de la misma acequia, denominados del Pla y del Río. El segundo territorio mencionado era una baronía señorial, de unas 5.000 tahúllas de huerta y un número indeterminado de almarjales (Bernabé, 2011a).

Aunque desde tiempos medievales el sobrecequiero de La Daya - o Daya Nuevaya había planteado algunos problemas a la jurisdicción de su homónimo oriolano, bien directamente, bien en la figura de su lugarteniente de Almoradí (Barrio, 1993:123-125), la supremacía del magistrado urbano en toda la zona dependiente del sistema de la acequia de Almoradí no admitía duda alguna. Entre 1571 y 1598, sin embargo, una serie de remodelaciones operadas en el azud de Alfaytamí y en la red de irrigación de su entorno traerán consigo una importante transformación de la jurisdicción de aguas en ese territorio. Así, la construcción de un nuevo azud en cantería y mampostería propició la apertura de dos nuevas boqueras de acequias por la margen izquierda y otra por la derecha. Esta última conllevó la excavación de un nuevo acueducto, denominado de Benijófar, que costearon los dominicos de Orihuela, para conducir el agua a la extensa heredad del mismo nombre que acababan de adquirir. Las dos tomas abiertas en la margen izquierda, sin embargo, no derivaron en la construcción de nuevas acequias, sino que se limitaron a abastecer a las ya existentes, cuyos caudales se vieron ahora notablemente incrementados, toda vez que las dotaciones procedentes de la lejana boquera oriolana resultaban claramente insuficientes (Bernabé, 2011a).

La mencionada remodelación, asociada a la nueva fábrica del azud de Alfaytamí, cristalizó en la constitución de una jurisdicción de aguas autónoma e independiente del sobrecequiero oriolano solo cuando la aldea de Almoradí consiguió alcanzar, en octubre de 1583, el privilegio de universidad separada de Orihuela. Al igual que en el obtenido por Callosa cuatro años atrás, nada se decía en él acerca de la figura del sobrecequiero; pero en el privilegio de insaculación otorgado en 1585 quedó regulado el procedimiento a seguir para la elección anual del nuevo oficio (Bernabé, 2011b, 151-152).

La segregación municipal sí se complementaba aquí, en cambio, con una profunda reordenación hidráulica que, al romper la tradicional dependencia con respecto al aprovisionamiento procedente de Orihuela, se tradujo en la emergencia de una jurisdicción de aguas desvinculada de la ciudad. De cara a una adecuada valoración sobre su significado, ha de advertirse que en la constitución de este nuevo sistema dependiente del azud de Alfaytamí no sólo primaron los intereses de los regantes que habitaban en Almoradí, sino que también alcanzaron destacado protagonismo un puñado de grandes propietarios ave- 
cindados en Orihuela, cuyos dominios venían teniendo serias dificultades para aprovechar el riego por el sistema tradicional, debido a su altitud e inadecuada disposición (Bernabé, 2011a). Curiosamente, aunque la jurisdicción de aguas tenía que recaer necesariamente a partir de entonces en un vecino de Almoradí - el sobrecequiero de la universidad, extraído anualmente por el procedimiento de la insaculación - , el órgano directivo de la comunidad de regantes, integrado por cinco electos, estuvo controlado durante buena parte del siglo XVII por oriolanos, entre los que destacaron representantes de instituciones eclesiásticas ${ }^{23}$.

Mas no todo el territorio irrigado por el sistema de Alfaytamí se correspondía exclusivamente con el término de huerta asignado a Almoradí tras su segregación. También abarcaba aquél algunas tierras pertenecientes al término municipal de Guardamar, de nula incidencia $-\mathrm{y}$, en consecuencia, sin interferencia alguna - a efectos de jurisdicción de aguas. Y, sobre todo, incluía en su integridad la baronía de Daya Nueva, que disponía tradicionalmente de su propio sobrecequiero, con jurisdicción limitada a cuestiones internas al señorío. Pero la nueva situación no tenía por qué mermar, en principio, las competencias señoriales o de sus oficiales. La inserción de Daya Nueva en el nuevo espacio jurisdiccional debió reproducir la posición que ya venía ocupando con anterioridad, definida por una relativa subordinación a la alcanzada por los sobrecequieros del realengo; ahora personificada por el de Almoradí. De hecho, era a éste a quien correspondía presidir las sesiones de la comunidad de regantes y en cuyo nombre se dictaban las resoluciones y demás disposiciones de aplicación general en todo el sistema del azud de Alfaytamí ${ }^{24}$. Unicamente a la hora de ejecutar determinadas actuaciones se recababa la colaboración del sobrecequiero de La Daya, por lógicas limitaciones de aquél para intervenir dentro de jurisdicción ajena ${ }^{25}$. Y la aparición en la misma zona de una nueva baronía - la Puebla de Rocamora, en 1629 - no modificó sustancialmente esta situación, al proceder de una amputación del término de Daya Nueva (Bernabé; 1985: 32-39); como apenas lo hizo - tampoco - la eclosión de colonizaciones alfonsinas a finales del Seiscientos, de alguna incidencia precisamente en esta zona de riegos.

\section{EL IMPACTO DE LAS COLONIZACIONES ALFONSINAS DEL SIGLO XVII Y DE LAS JURISDICCIONES GUBERNATORIO NOMINE}

La tardía colonización, generalmente mediante establecimientos enfiteúticos, de una simple heredad o de un antiguo señorío de jurisdicción civil - cuya lejana despoblación habría incapacitado anteriormente a su titular para reclamar las competencias expresadas en el fuero 78, rúbrica de jurisdictione omnium judicum, otorgado por el rey Alfonso de Aragón en 1329-, no debía tener, en principio, mayores consecuencias de relieve en materia de jurisdicción de aguas que las ya mencionadas para los casos de Redován, Cox y La Granja. Como es suficientemente conocido, a lo largo del siglo XVII un total de ocho

23 AJPAAA: Mâ de determinacions y provisions fetes per los elets dels hereters regants del Azud de Alfaytami desde lo any 1665 en avant, Las actas correspondientes abarcan solamente los periodos comprendidos entre el 01-05-1665 y el 13-0-1681; y entre el 07-06-1694 y el 25-05-1704. Naturalmente, también la presencia del elemento clerical se justificaba por su condición de regantes. Fueron miembros habituales de dicha junta el Lugarteniente de la Gobernación D. Luis Togores, varios juristas oriolanos vinculados al tribunal de dicha institución, el rector del Colegio de Predicadores, el prior del convento de san Agustín, el síndico del convento de San Juan; todos ellos oriolanos. También solían formar parte, el corrector del convento de san Francisco de Paula de Almoradí y, en la última etapa, el párroco del señorío alfonsino de Formentera. No ha de extrañar, por tanto, que en muchas ocasiones la junta se celebrase en Orihuela, en lugar de hacerlo en Almoradí.

24 Ibídem; y copias de varias juntas generales de regantes celebradas entre las décadas de 1590 y 1630 , en AHN: Consejos. Leg. 21.930; ARV: Real Audiencia. Procesos $3^{a}$ parte, n. 2.377; AHO: Sec. Colegio, L-224, pássim.

25 Así ocurrió, por ejemplo, en 1618, con motivo de una ejecución por deudas en bienes del propio señor de la Daya. AMO: Sobrecequiero. $N^{\circ} 69$, ff. 355-258. 
dominios experimentaron procesos colonizadores en el Bajo Segura, al amparo del privilegio alfonsino, con el resultado de la aparición de otros tantos núcleos señoriales, de los que todos, menos uno, se ubicaban en la huerta tradicional (Pla, 1993; Gil Olcina, 1999; Bernabé, 1993c). Con ello, debieron surgir otros tantos nuevos sobrecequieros $-\mathrm{u}$ oficiales afines - para ocuparse de los asuntos de aguas que se suscitaran dentro de las nuevas entidades municipales ${ }^{26}$; bien entendido que en caso de conflicto con instancias externas correspondía al de Orihuela su conocimiento. Así lo había declarado una sentencia de la Audiencia de Valencia de 29 de mayo de 1618 - ya mencionada_, sentando jurisprudencia que pocos ignoraron.

Solo una de aquellas colonizaciones - la de Benejúzar, incluida en el sistema de la ya denominada acequia Vieja de Almoradí - se produjo antes de esta fecha, pues se inició, con población morisca, en 1607; por lo que hubo que repoblar al poco tiempo, mediante carta de población otorgada en 1611. Mas no por ello su titular, D. Jaime Rosell, dio muestras de aspirar, por el momento, a mayores competencias jurisdiccionales en materia específica de aguas. Sí habría de conseguir al poco tiempo, no obstante, desde su cargo de Lugarteniente de la Gobernación, que la Corona enviase - en 1623 - un visitador de las aguas de la huerta de Orihuela, con la finalidad, entre otros objetivos, de reformar la gestión del regadío y realizar nuevos repartos de aguas; de los que saldría especialmente beneficiado su señorío (Casey, 1976). Y también logró, amparándose en su condición de oficial real, que se le incrementara la jurisdicción señorial, al obtener en 1628 - tras haberlo intentado infructuosamente ya en 1608 y 1614- el mero imperio titulo gubernatorio nomine hasta las cortes siguientes, celebradas en 1645; en que se le renovó nuevamente, en atención siempre a sus buenos servicios ${ }^{27}$. En realidad, las implicaciones de la jurisdicción señorial de mero imperio otorgada titulo gubernatorio nomine sobre los asuntos de aguas no estaban suficientemente delimitadas; y el hecho de que algunos señores alfonsinos trataran de obtener aquélla, a cambio de cuantiosos servicios en metálico - además de otros de diverso tipo - sugiere que también en esta materia su adquisición podía tener alguna consecuencia positiva para su titular. $\mathrm{O}$, al menos, les permitía albergar algunas esperanzas al respecto

En 1629 D. Juan Ruiz, señor de Cox, acudió al Consejo de Aragón, invocando la reciente merced obtenida por su paisano D. Jaime Rosell, para solicitar también - con éxito inmediato - la jurisdicción de mero imperio gubernatorio nomine sobre su dominio alfonsino, ofreciendo la misma cantidad de 1.000 libras con que aquél había servido ${ }^{28}$. Resulta difícil saber si el de Cox estaba pensando entonces en la posible repercusión de ese reforzamiento jurisdiccional sobre los asuntos de aguas. Pero, en algún momento posterior, sí parece que trató de hacer valer el superior rango jurisdiccional alcanzado. En 1641, con motivo de una sentencia condenatoria pronunciada por el sobrecequiero de Orihuela contra un vasallo de Cox, previa denuncia interpuesta por uno de Albatera, el señor no dudó en enarbolar la sentencia de la Audiencia obtenida por Callosa en 11 de julio de 1628 -en pleito contra vecinos de Catral - para reclamar la causa, por entender que competía a la jurisdicción del reo $^{29}$. Es de prever que el proceso no tuviera ulterior recorrido, ya que la oportuna invocación de la sentencia de la Audiencia de 1618 - la que realmente venía

26 La escasez de cartas de población conocidas para estos señoríos impide, por el momento, precisar más la cuestión. Hay mención expresa a la figura del sobrecequiero en la correspondiente a Molins (Bernabé, 1982:209) y Bigastro (Canales, 1981, 69).

27 Millán, 1984: 96-97; ACA: CA: Leg. 653, doc. 21/2-4; Leg. 633, doc. 2/2-6, Leg. 872, doc. 67; leg 891 , doc. 81 .

28 ACA: CA: Leg. 619, doc. 14.

29 AMO: $N^{o} 1.415$, ff. 180-187. 
al caso - por parte del sobrecequiero de Orihuela debió obrar sus efectos. Pero resultaba difícil sustraerse a la tentación de conseguir algo más en esta materia.

El contenido de cierta petición expresada ante el Consejo de Aragón por uno de sus propios miembros - el Conde de Albatera - en 1645 constituye otro claro indicio de las dudas que suscitaba el alcance jurisdiccional, en materia de aguas, de este tipo de concesiones señoriales; al tiempo que resulta indicativo de lo delicado del tema y de la especial sensibilidad que despertaba. El motivo que había originado la solicitud del de Albatera no era otro que haber «entendido que por parte del Conde de La Granja Don Francisco Rocamora y también por la de Don Francisco Ruiz, Señor de Cox, se pretende suplicar a S.M. la jurisdicción titulo gubernativo nomine en dichos lugares». Aunque aparentemente se trataba de un asunto que no tenía por qué afectarle directamente, consideró necesario, sin embargo, traer a colación la sentencia de 29 de mayo de 1618, y recordar «que el juez sobrecequiero de la ciudad de Orihuela es a quien toca el ser juez de los excessos que por razón de las aguas suceden en los lugares de Cox y La Granja y acude la villa de Albatera a pedir justicia cuando le quitan el agua o sucede otro qualquier accidente en razón del gobierno della en que es interesado el regio fisco». Por consiguiente, para evitar posibles e irreparables malentendidos, solicitaba que «en las dichas mercedes se declare no ser la intención hacer novedad en perjuicio del suplicante ni en lo juzgado de dicha sentencia, porque todo lo tocante a las dichas aguas se ha de juzgar por el juez sobrecequiero de Orihuela en los lugares de Cox y La Granja ${ }^{30}$. Como poseedor del mero imperio sobre Albatera - desde tiempos medievales - , el Conde debía saber que la jurisdicción de aguas se regía por otros criterios; pero desconfiaba de las implicaciones que pudiera tener en esta materia cualquier alteración de la articulación jurisdiccional vigente - a todos los niveles - en el sistema de la acequia de Callosa. De ahí sus recelos ante las peticiones de la gubernatorio nomine por parte de los señores vecinos.

Con una jurisdicción de aguas regulada, en gran medida, por las mencionadas sentencias de 1618 y 1628, el sistema de la acequia de Callosa no habría de conocer en lo sucesivo nuevas modificaciones señoriales, pues la tentativa ensayada por el caballero oriolano y secretario de su consistorio Ginés Juan Portillo, a finales de la centuria, en la cola de la acequia de Catral, para desecar almarjales y proceder a una probable colonización alfonsina, no llegó finalmente a prosperar (Millán, 1984: 102, 110-112). Fue en otros sistemas de acequias donde tuvieron lugar las iniciativas colonizadoras. Así, en la mencionada acequia Vieja de Almoradí se producirá, además de la ya aludida repoblación de Benejúzar, la de Rafal, en 1636, con riego de la arroba de San Bartolomé, que no parece suscitara especiales problemas jurisdiccionales. En el sistema de la acequia de Alquibla, que discurría por la margen derecha del Segura - y abastecía también una porción de Benejúzar ubicada en esa orilla del río - emergió, ya avanzada la segunda mitad del siglo XVII, el señorío alfonsino de Jacarilla y, nada más iniciarse la nueva centuria, el de Bigastro. Poco antes había tenido lugar la colonización del de Molins, que irrigaba a través de la acequia de los Huertos, también en la margen derecha. Y, en ese mismo contexto cronológico, pero en territorio algo más alejado, se erigieron los señoríos de Formentera y Benijófar, fuera ya del ámbito jurisdiccional del sobrecequiero de Orihuela.

La base territorial de Formentera se inscribía en una elevada proporción en el sistema del azud de Alfaytamí; pero también se beneficiaba tradicionalmente de las aguas procedentes del sistema del azud de Rojales, quizás a través de una acequia propia cuyo origen resulta difícil datar. Mención aparte del hipotético sobrecequiero señorial para asuntos internos, esta doble dependencia hídrica la colocaba también bajo la jurisdicción de los correspondientes

\footnotetext{
30 ACA: CA: Leg. 659, doc. 77/2.
} 
sobrecequieros de Almoradí y Guardamar; al menos antes de que consiguiera - como en algún momento indeterminado, efectivamente, ocurrió - un abastecimiento independiente mediante la construcción de un azud propio, posiblemente en colaboración con el dueño de Benijófar ${ }^{31}$. Llegado este momento, Formentera pudo romper quizá su dependencia jurisdiccional en materia de aguas con respecto a Guardamar; pero no así, al menos en el período aquí considerado, respecto de Azud del Alfaytamí, en cuya junta directiva solía estar representada a través de su párroco ${ }^{32}$.

La disposición de una infraestructura hidráulica propia y autosuficiente, capaz de suministrar el agua necesaria y de conducirla sin interferencias de elementos extraños otorgaba una relativa independencia jurisdiccional a cualquier dominio. El caso de Benijófar, ubicada en la margen derecha del río Segura, justo enfrente de Formentera, responde a esta caracterización en el momento de producirse su colonización alfonsina, en 1689. Aunque esta heredad se irrigaba tradicionalmente a través de la acequia de Alquibla, cuya lejana boquera se ubicaba junto a la frontera murciana, en 1538 su dueño había recibido autorización de la ciudad de Orihuela para levantar un azud - de estacada - e instalar una noria, al objeto de ampliar y mejorar su riego ${ }^{33}$. Desde 1586 , no obstante, la base territorial de la heredad se irrigaba ya de una acequia propia, tributaria del azud de Alfaytamí, del que la separaban varios kilómetros de distancia. Los dominicos de Orihuela, que habían excavado a su costa, atravesando terrenos ajenos, este acueducto, nada más hacerse con la propiedad de la heredad, lo abandonaron definitivamente en 1671 - por su elevado coste de mantenimiento - , al tiempo que recuperaban la antigua noria, con su correspondiente canal de conducción y distribución ${ }^{34}$. Fue el preludio de la inmediata venta de la heredad a Jaime Gallego - en 1686 - ; quien al poco tiempo procedió a su colonización alfonsina (Culiañez, 2007). Es posible que por entonces Benijófar hubiera comenzado a servirse nuevamente de su antiguo azud, aunque fuera de estacada; lo que le habría exonerado de someterse a jurisdicciones de aguas extrañas.

La multiplicación de entidades señoriales, de jurisdicción alfonsina, baronal o gubernatorio nomine, junto a las segregaciones municipales protagonizadas por aldeas realengas dependientes, abocaron al antiguo término general de Orihuela a un proceso de disgregación territorial y jurisdiccional - inacabado en época foral - de importantes consecuencias, que amenazaba con alterar seriamente el mantenimiento de los equilibrios internos en cuyo marco se había venido desenvolviendo la dinámica hidráulica. El óptimo aprovechamiento de los recursos hídricos y, sobre todo, la viabilidad de cualquier modelo de expansión o, al menos, de estabilización agraria sostenible exigía probablemente, tanto una gradual fragmentación de las unidades de gestión en materia de riegos, como una cierta centralización de la jurisdicción de aguas, especialmente en épocas de severas dificultades económicas, como fueron las décadas centrales del Seiscientos. Ante las tendencias centrífugas que dispersaban las células de poder hidráulico y erosionaban la capacidad de respuesta unitaria a los retos planteados por la acumulación de problemas puntuales, se hizo necesario arbitrar

31 ROCA DE TOGORES, 1832. Señala este autor que dicho azud se fabricó en 1659, en virtud de convenio entre los dueños de Formentera y Benijófar. Pero dicha fecha resulta difícil de aceptar, si atendemos a lo que a continuación se dirá respecto a esta segunda heredad.

32 Vid. supra, nota 24.

33 AMO: Contestador de 1538, ff. 105-107.

34 La información sobre el abandono de la acequia de Benijófar por parte del Colegio de Predicadores de Orihuela y la recuperación de su antiguo riego, mediante la reparación de la noria y del azud, procede fundamentalmente de un documento de los fondos de la Gobernación de Orihuela, que consulté antes de su catalogación, y que posteriormente no he conseguido localizar para citarlo con su signatura actual. De todas formas, en el Libro de Consejos del Colegio (AHO), en f. 103, está el acta de la sesión celebrada el 2 de mayo de 1664, en que se resolvió emprender aquella iniciativa. 
fórmulas capaces de restablecer una cierta coherencia interna en el funcionamiento de todo el macrosistema del Bajo Segura y de aunar y coordinar esfuerzos para la consecución de objetivos comunes; a ser posible, bajo la batuta de un único juez.

\section{REACCIÓN CENTRÍPETA: DE LA VISITA DE MINGOT A LA CARTA REAL DE 1699}

Tras los primeros síntomas de dificultades económicas que se cernían sobre buena parte de la huerta, una vez expulsados los moriscos, y mucho antes de asistir a la oleada finisecular de colonizaciones alfonsinas - más estrechamente vinculadas, por otra parte, con etapas de recuperación agraria - , comenzaron a oírse voces que reclamaban una reforma en el sistema de limpieza y mantenimiento de la red hidráulica. La reciente introducción del sistema de arrendamiento de las mondas al mejor postor por parte de las distintas comunidades de regantes estaba generando un encarecimiento galopante de los costes, al tiempo que una excesiva demora en su ejecución, con el consiguiente perjuicio a los regantes y a los cultivos. En 1612 se planteó la posibilidad de crear un nuevo oficio municipal en la ciudad - distinto del sobrecequiero-, que estuviera encargado de gestionar la conservación y limpieza de todas las acequias, dividiendo la huerta en porciones - o quarters - y con poderes suficientes para exigir a cada regante la cuota o derrama aplicada en proporción a la cantidad de tierra poseída para la contratación del personal encargado de realizar las mondas ${ }^{35}$. Aunque, en realidad, se trataba de reponer una figura ya existente en época medieval - tal como se contemplaba, por ejemplo, en el privilegio insaculatorio de 1445 (Bernabé 2011b, 309) - , no parece que la propuesta encontrara ahora mucho eco, puesto que seis años más tarde era el prior del convento de San Agustin, padre Jaume Sanchez, quien volvía sobre el tema, precisando el método a aplicar como alternativo al arrendamiento. En el nuevo diseño, no se consideraba necesario nombrar un nuevo oficial, pues bastaba con el sobrecequiero, pero eran los síndicos de las acequias quienes debían asumir la gestión de las mondas ${ }^{36}$. Tras el nombramiento de una comisión encargada de disponer lo más conveniente para su ejecución, la experiencia parece que no resultó satisfactoria; de modo que en 1620, tras haberse llegado incluso a elaborar nuevas ordenanzas para el gobierno de las aguas - aprobadas por la Audiencia de Valencia el 16 de mayo de 1619-, el consell oriolano decidió dar marcha atrás ${ }^{37}$. Atendiendo, pues, la correspondiente solicitud, una provisión de la Audiencia, de 30 de marzo de 1621, revocaba las novedades producidas ${ }^{38}$.

En realidad, tras el debate sobre la organización de las mondas subyacía la necesidad de arbitrar mecanismos que detuvieran el progresivo deterioro que estaba experimentando la huerta como consecuencia de una serie encadenada de circunstancias desfavorables y de problemas estructurales - en cuyo análisis no podemos detenernos ahora -, y que acabó determinando el envío, por la Corona, de un juez visitador. De la intensa y variada actividad desplegada por el comisario Dr. Jerónimo Mingot entre finales de septiembre de 1623 y principios del verano de 1624 interesa destacar aquí las ordenanzas de riego que promulgó - cuya vigencia se ha mantenido en múltiples aspectos hasta fechas recientes - ; y muy particularmente los capítulos 4, 5, 7, 12, 30, 31, 35, 36 y 37 de las mismas. En ellas se menciona, una y otra vez, a los sobrecequieros de Orihuela, Callosa, Almoradí y Guardamar, con alguna referencia también - algo marginal- a los de los »lochs de sa contribució»-que podemos identificar con los señoriales-, como destinatarios de los

35 AMO: Contestador de 1612, f. 257v.

36 AMO: Contestador de 1618, ff. 129-131v.

37 AMO: Contestador de 1620, f. 106. ACA: CA: Leg. 615, doc. 4/68.

38 BUV: TAGELL: Epitome...., let. A, n 328. 
nuevos estatutos y responsables de su cumplimiento. Y, de los capítulos mencionados, fue el de mayor trascendencia el que, de forma extractada, establecia lo siguiente:

«Ittem per que ha constat que lo sobresequier de la ciutat de Oriola y de les universitats de Callosa, Almoradi y Guardamar y altres llochs que están dins los termens generals de la ciutat han acostumat tenir per sos acessors a los mateixos escrivans que tenen arrendats les corts de dits sobresequiers.....ordena y mana.... que lo sobrecequier de la ciutat de Oriola en lo comensament de son offissi aja de nomenar una persona perita en drets per son assessor, a consell de la qual determine totes les causes tocants a son offici, y que los sobrecequiers de dites universitats coneguen de ses causes a concell dels advocats que les dites universitats respective tenen en la ciutat de Oriola, aço fins que Sa Magestat nomene jutge assessor, com es convenient, per la bona administració de les aygues de la dita ciutat de Oriola y universitats de sa contribución ${ }^{39}$.

El estatuto 30 comportaba, en consecuencia, la tecnificación de la impartición de la justicia de aguas y un paso decisivo en el proceso de concentración jurisdiccional, al tiempo que preveía un control inminente por parte de la Corona del oficio que ahora se erigía en principal protagonista. Es por todo ello que contara con la inmediata desaprobación de un cualificado sector de los regantes, que se manifestó claramente a favor del mantenimiento de la tradicional descentralización y del procedimiento rápido y sumario para la resolución de los conflictos de aguas ${ }^{40}$. Pero la decisión real acerca de la aplicación de las nuevas ordenanzas era firme. Por el momento, no obstante, la designación del asesor - ahora necesariamente un letrado- continuó en manos del sobrecequiero oriolano; hasta que en 1635 intervino nuevamente el Dr. Mingot para expresar al Consejo que

«no se guardan los dichos estatutos, y hay en Origuela, en la administración y repartición de las aguas, el mesmo daño que antes, por falta de assessor; que el que nombran los sobrecequieros, como es anual, por no encontrarse con los poderosos y ricos que no guardan las reparticiones ni acuden a pagar las mondas, no se atreve a hazer justicia; que si fuese asesor en propiedad nombrado por V. Magd. tendría más autoridad para la execución de dichos estatutos ${ }^{41}$.

En respuesta a esta insinuación se dictó real resolución el 12 de septiembre de dicho año, que encomendaba la asesoría jurídica del sobrecequiero al actual asesor de la Gobernación. Diez años más tarde de haberse planteado la necesidad de reforzar la jurisdicción de aguas, se daba un nuevo paso decisivo en aquella dirección, puesto que, en la práctica, conllevó su vinculación orgánica a la administración real. En adelante, la asesoría del sobrecequiero de Orihuela y de todos los sobrecequieros de la huerta quedó incorporada a la de la Gobernación, que era de provisión regia y renovación trianual (Bernabé, 1997). La Corona, al tiempo que establecía la centralización efectiva de la jurisdicción de aguas, se hacía de esta guisa con el control de un oficio de origen municipal.

Las consecuencias de esta profunda reforma no tardarían en dejarse sentir y en suscitar las correspondientes protestas. Concretamente, fue el municipio realengo de Callosa, como

39 Capítulo 30 de las Ordenanzas de Mingot. Manejo una copia existente en AHN: Clero, Libro n ${ }^{\circ} 389$, ff. 53-64v. Existe versión en castellano publicada en tiempos recientes, con breve estudio introductorio (Nieto, 1980).

40 ACA: CA: Leg. 615, doc. 4/68.

41 ACA: CA: Leg. 711, doc. 25. 
uno de los principales afectados - debido a su inserción en el sistema de la acequia homónima, controlada directamente desde la ciudad-, el que entabló al poco tiempo pleito sobre el particular. Precisamente en 1638 los callosinos habían conseguido de la Corona, previo pago de un cuantioso servicio en metálico, el privilegio de villazgo, que comportaba la independencia plena respecto de Orihuela, con la obtención - entre otras prerrogativas del mero imperio. De entre los 41 capítulos de que constaba el documento, el número 17 aludía expresamente a la jurisdicción de aguas, al abordar la figura del sobrecequiero, en una línea coherente con la sentencia de 1628. La jurisdicción que ahora se le reconocía - a petición del municipio - era, en teoría, la acostumbrada: «conexent com coneix de tots los danys de aygua que.s faran dins lo terme de la dita vila, sens que dels vehins de la dita vila se puixa clamar en altra part, de manera que lo actor segueixca lo for del reo» (Navarro, 2001: 184). Sin embargo, en virtud de la reforma operada recientemente a instancia de Mingot, denunciaba el síndico de Callosa ante el Consejo de Aragón, en 1641, que

«el asesor del Governador de dicha ciudad pretende serlo del sobrecequiero de la dicha villa, haciendo autos en razón de las mondas y de lo demás tocante al dicho sobrecequiero, y como reside en la dicha ciudad, han de acudir a ella los vecinos de la villa a pedirle justicia, desaforándolos con esta incomodidad, con menoscabo de sus haziendas y atribuyendo a la ciudad la jurisdicción que no la toca» ${ }^{42}$.

En el pleito subsiguiente, instado unos meses más tarde contra dicho asesor ante la Audiencia de Valencia, se quejaba Callosa de que su reciente promoción a la categoría de villazgo habría servido de poco en lo tocante a las aguas, «puix en materia jurídica lo sobrecequier seria ningú». Y, en una valoración quizás inadecuada - - por excesivamente victimista - del alcance de la disposición de 1635, trataba de vincular la figura del asesor de la Gobernación con los poderosos intereses de los regantes oriolanos. Contradijo sus planteamientos el asesor - el Dr. March Antoni Bisse-, haciendo ver que él solo proporcionaba consejo a los sobrecequieros, incluido el de Callosa, que eran los verdaderos titulares de la jurisdicción ${ }^{43}$. Podía haber añadido también que, para garantizar la imparcialidad de su proceder, el oficio de asesor, de duración trianual, venía recayendo sistemáticamente en juristas procedentes de fuera de la Gobernación. Y, como no obtuviera entonces sentencia favorable, en 1645 acudía nuevamente Callosa ante el Consejo de Aragón. Tras alegar los derechos que la asistían - los mismos que se incluyeron en el sumario del reciente proceso-, culpaba ahora expresamente a la ciudad de Orihuela del menoscabo experimentado, porque

«callando todo lo referido, en el año 1635 obtuvo una Real Carta mandando que el asesor del Governador lo fuese de las causas del sobrecequiero, privándole del todo de la jurisdicción que por privilexios, ordinaciones y sentencia le estava concedida y juntamente de la posesión en que estava dicha villa, causándola a ella y a todos sus vecinos infinitas costas y dicenciones con los de la dicha ciudad».

Agotada la vía de justicia, acababa solicitando por la vía de gracia - basada en el consabido intercambio de servicios por mercedes - simplemente «la haga merced de mandarla manutener en su posesión, en consideración de haverle servido con 12.500 ducados por los privilexios de universidad y villa, y por lo que ha servido en las levas, assi con gente

42 ACA: CA: Leg. 883, doc. 116/1.

43 ARV: Real Audiencia. Procesos $1^{a}$ parte, S/3.519. 
como con dinero ${ }^{44}$. Mas todo resultó inútil, pues la Corona - con el previsible apoyo de la ciudad de Orihuela - no estaba dispuesta a reconsiderar la centralización jurisdiccional instaurada, que permitía ejercer a uno de sus más importantes oficiales en el sur valenciano un mayor control sobre el macrosistema hidráulico en general.

Y no fue solamente la villa de Callosa la única afectada. También el sobrecequiero de Almoradí, pese a la independencia efectiva de que venía gozando en la gestión del sistema de Alfaytamí, debió experimentar algún tipo de limitación en sus atribuciones jurisdiccionales, al tener que compartir algunas de éstas con el asesor de la Gobernación. A falta, por el momento, de otra documentación más explícita al respecto, puede afirmarse que ninguno de estos dos oficiales solía participar en las juntas de electos de la comunidad de regantes celebradas en el último tercio del siglo XVII; pero sí -ambos magistrados - en las juntas generales. Además de proporcionar, seguramente de forma ordinaria - aunque mediatizada por la distancia entre ambas poblaciones - , asesoramiento letrado a las actuaciones judiciales del sobrecequiero de Almoradí, dicho asesor también participaba en decisiones concernientes al sistema de irrigación del azud de Alfaytamín ${ }^{45}$.

Más improbable resulta, en cambio, que esta labor consistente en dar consejo y declarar el derecho a los titulares de la jurisdicción pudiera llevarse a cabo de forma efectiva en el marco señorial, donde los sobrecequieros locales continuaron ocupándose, sin el concurso de aquél, de los asuntos internos. En consecuencia, la perseguida centralización jurisdiccional difícilmente podía resultar operativa en los señoríos, que debieron quedar excluidos de la interferencia del asesor de la Gobernación, salvo en las materias que afectaban a más de una comunidad.

En un contexto marcado, en las décadas centrales de la centuria, por una progresiva relajación en el cumplimiento estricto de las ordenanzas de Mingot, la llegada de un nuevo asesor, Dr. Laureano Martínez de la Vega, provocó en 1663 un episodio de hondas repercusiones en la dirección que se viene apuntando. Decidido a no condescender con la práctica que se venía aplicando, tras inspeccionar los papeles del tribunal del sobrecequiero, el asesor trató de remover en torno a un centenar y medio de denuncias que habían sido condonadas o «remitidas» durante los últimos seis años sin el concurso expreso de sus predecesores en el oficio. Su actitud acabó provocando un serio conflicto en la ciudad, con graves altercados en el consell, que determinaron la apertura de una investigación por parte de la administración real para recabar información y depurar responsabilidades. El resultado final fue un reforzamiento de la figura del asesor, sin cuya asistencia los sobrecequieros vieron muy limitadas, a partir de entonces, su capacidad de decisión. Una carta real de 8 de abril de 1663 prohibió al titular de la jurisdicción de aguas hacer remisiones de penas sin consentimiento del asesor, al tiempo que declaraba nulidad de las firmas de derecho que pudieran iniciarse contra dicho oficial sin citación del procurador fiscal, por tratarse de «materias que interesa mi Real Patrimonio y regalías» ${ }^{46}$.

Pero la culminación del encumbramiento de esta figura - siempre en lo referente a los asuntos de aguas - se produciría en 1699; y aparece estrechamente ligada a problemas de insuficiencia jurisdiccional que atenazaban al sobrecequiero de Almoradí para hacer efectivo

44 ACA: CA: Leg. 892, doc. 123/1

45 En 1657-58, por ejemplo, varias provisiones y sentencias del sobrecequiero de Almoradí contaron con el consejo del asesor de la Gobernación (AJPAAA: Leg. 17, «El Colegio de Predicadores de Orihuela contra el síndico del azud de Alfaytamí»). Y en 1658 era el Conde de Albatera quien solicitaba que se ordenase a dicho asesor dispusiera lo necesario para conseguir que se mondaran las acequias y azarbes de la universidad de Almoradí, pues al desbordarse las aguas y anegarse los caminos por la negligencia del sobrecequiero se entorpecía la comunicación con su señorío de Albatera (ACA: CA: Leg. 906, doc. 107). También, supra, nota 18.

46 ACA: CA: Leg. 758, doc. 1-5; ARV: Real, reg. 590, f. 403; AMO: Contestador de 1663, ff. 151-153, $243 \mathrm{v}-245 \mathrm{v} ; N^{o} 2033$, ff. 264-265v 
su dominio sobre el sistema del azud de Alfaytamí. Abrumada por el enorme peso de las deudas que recaían sobre la mencionada comunidad de regantes -21.354 libras de principal-, en 1698 se aprobó un plan para su gradual liquidación, que incluía el establecimiento de una serie de derramas anuales, en proporción a la tierra poseída. Según informaba el síndico de los regantes al Consejo de Aragón - cuyo apoyo suplicaban-, el esfuerzo resultaría inútil si no se conseguía vencer la resistencia de los barones de Daya Nueva y la Puebla - entre otros grandes propietarios - , quienes, por diversos motivos, se negaban a contribuir e incluso impedían la entrada en sus dominios a los agrimensores que debían llevar a cabo la preceptiva medición de las tierras. Ante la incapacidad del sobrecequiero de Almoradí para hacer valer su autoridad, solicitaban concretamente los regantes

«sea de su Real clemencia mandar al Assesor de aquella Governacion..... ponga en execución todos los Reales Estatutos, sin excepción de personas; mande se sogueen todas las tierras de dicho Heredamiento.....ponga en tanda el agua de la Azequia mayor de aquella huerta, por estarlo ya la azequia que llaman del Río, distribuyendo con equidad a cada uno, según el número de sus taúllas, para que conforme la utilidad que perciben del riego, contribuyan en las derramas que se impondrán; executando todas las penas expressadas en dichos Reales Estatutos» ${ }^{47}$.

En definitiva, lo que se pedía era que el asesor asumiera directamente todas las competencias propias de la jurisdicción de aguas en el macrosistema de Alfaytamí. Y así fue decretado, en efecto, mediante real orden de 31 de enero de 1699, que, tras un examen de los estatutos y de su aplicación - y realizadas las correspondientes consultas - deducía «es juez peculiar el Assessor, y como tal en primera instancia reside los pleitos que por razón de las aguas se subsitan...y que esta orden la execute el azessor como juez y no en virtud de comisión mía, por el inconbeniente de los recursos $»^{48}$. Nunca, hasta entonces, este oficial real había alcanzado, de forma expresa, tales niveles de atribuciones jurisdiccionales, que le situaban claramente por encima del sobrecequiero.

La inminencia de la Guerra de Sucesión quizás contribuyera a impedir que aquél culminara la labor que le había sido encomendada. Pero cuando, acabada la contienda, la nueva administración borbónica decidió unificar y concentrar toda la jurisdicción de aguas del Bajo Segura en la figura del alcalde mayor de Orihuela, el precedente al que se acogió para justificar la coherencia de dicha medida con la práctica observada en la época anterior fue, expresamente, la real orden de 31 de enero de 1699; que permitía, además, presentar a aquel oficial como el heredero directo de la extinta figura del asesor de la Gobernación (Bernabé, 2004).

A modo de conclusión y de balance final, las transformaciones operadas en los espacios jurisdiccionales relativos al regadío durante los siglos XVI y XVII significaron una dispersión desigual de las instancias de gestión interna correspondientes a los diferentes sistemas de acequias, ligada a los procesos de segregación municipal operados en el antiguo término general de la ciudad de Orihuela y a la construcción de azudes; pero, al mismo tiempo, el mantenimiento de una jurisdicción de aguas centralizada, con la importante novedad que supuso su control directo por parte de la Corona.

47 ACA: CA: leg. 856; doc. 28/1-33.

48 AHN: Clero, Libro 389, ff. 49-48v. 


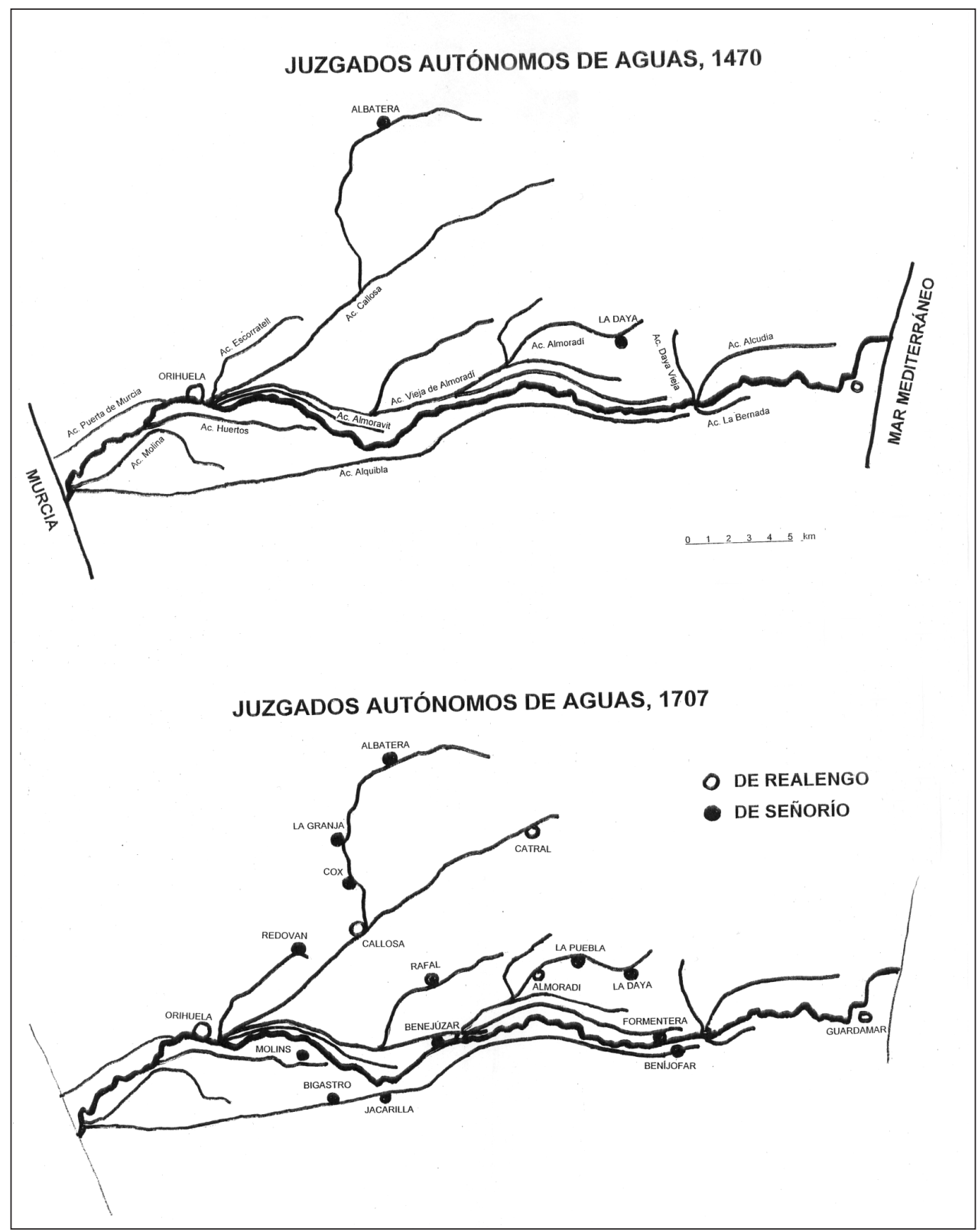

FIGURA 1. Juzgados autónomos de aguas 1470-1707. Elaboración propia. 


\section{ABREVIATURAS}

ACA: CA: Archivo de la Corona de Aragón: Consejo de Aragón

AHN: Archivo Histórico Nacional

AHO: Archivo Histórico de Orihuela

AJPAAA: Archivo del Juzgado Privativo de Aguas del Azud de Alfaytamí

AMO: Archivo Municipal de Orihuela

ARV: Archivo del Reino de Valencia

BUV: Biblioteca Universitaria de Valencia

\section{BIBLIOGRAFÍA CITADA}

BARRIO BARRIO, J.A. (1993): «El señorío de La Daya y el municipio de Orihuela en el siglo XV»; en Señorío y feudalismo en la Península Ibérica (ss. XII-XIX), vol. III, Institución Fernando el Católico, Zaragoza, pp. 259-270.

BERNABÉ GIL, D. (1982): Tierra y sociedad en el Bajo Segura (1700-1750), CAPAUniversidad de Alicante, Alicante, $241 \mathrm{pp}$.

BERNABÉ GIL, D. (1985): «La formación de un patrimonio nobiliario en el Seiscientos valenciano. El primer Marqués de Rafal», Revista de Historia Moderna, nº 5, pp. 11-66

BERNABÉ GIL, D. (1988): «Universidades y villas. Notas sobre el proceso de segregación municipal en el realengo valenciano (siglos XVI y XVII), Revista de Historia Moderna, $n^{\circ} 6 / 7$, pp. 11-38.

BERNABÉ GIL, D. (1992): «Los Santángel, señores alfonsinos. Aspectos de una colonización señorial en territorio realengo», en LLuís de Santàngel i el seu temps, Ajuntament de València, Valencia, pp. 55-67.

BERNABÉ GIL, D. (1993a): «Una coexistencia conflictiva: municipios realengos y señoríos de su contribución general en la Valencia foral», Revista de Historia Moderna, $\mathrm{n}^{\circ} 12$, pp. 11-77.

BERNABÉ GIL, D. (1993b): «Sobre el origen territorial en los señoríos valencianos de colonización alfonsina», en Señorío y feudalismo en la Península Ibérica (ss. XII-XIX), vol. IV, Institución Fernando el Católico, Zaragoza, pp. 123-138.

BERNABÉ GIL, D. (1997): «Oficiales de la Gobernación General y oligarquía municipal en Orihuela durante el siglo XVII», en FERNÁNDEZ ALBALADEJO, P (ed.): Monarquía, Imperio y Pueblos en la España Moderna, C.A.M.-Universidad de Alicante, A.E.H.M., Alicante, pp. 569-582.

BERNABÉ GIL, D. (1999): «Aspectos sociales del crecimiento agrario valenciano en tiempos de Felipe II», en BELENGUER CEBRIÀ, E. (Coord.): Felipe II y el Mediterráneo I- Los recursos humanos y materiales, vol. I, Sociedad Estatal para la Conmemoración de los Centenarios de Felipe II y Carlos V, Madrid, pp. 179-193.

BERNABÉ GIL, D. (2004): «Repercusiones del cambio dinástico sobre los Juzgados de Aguas del Bajo Segura», en ALVAR, A.; CONTRERAS, J. y RUIZ, J.I. (eds.): Política y cultura en la época moderna, Universidad de Alcalá-F.E.H.M., Alcalá de Henares, pp. 419-430.

BERNABÉ GIL, D. (2011a): «Técnica hidráulica y regadío en el Bajo Segura: La construccion del azud de Alfaytamí y las remodelaciones en la red de irrigación (1571-1598)», Revista de Historia Moderna, $\mathrm{n}^{\circ}$ 29, pp. 11-38.

BERNABÉ GIL, D. (2011b): Privilegios de insaculación otorgados a municipios valencianos en época foral, Instituto Juan Gil-Albert, Alicante. 
CANALES MARTÍNEZ; G. (1981): «Creación del señorío eclesiástico de Bigastro (17011715)», en La propiedad de la tierra en España, Facultad de Filosofía y Letras, Alicante, pp. 65-73.

CASEY; J. (1976): «Irrigació i economía al Pais Valencià (1589-1689)», en primer Congreso de Historia del País Valenciano, vol. III, Valencia, pp. 281-289.

DEL ESTAL, J.M. (1982): Conquista y anexión de las tierras de Alicante, Elche, Orihuela y Guardamar al Reino de valencia por Jaime II de Aragón (1296-1308), Caja de Ahorros Provincial, Alicante, $423 \mathrm{pp}$.

GIL OLCINA, A. (1986): «Jurisdicción alfonsina y poblamiento valenciano», Cuadernos de Geografía, no 39-40, pp. 235-246

GIL OLCINA, A. (1999): «Fuero y jurisdicción alfonsinos en la génesis de municipios valencianos», Estudios Geográficos, vol. 60, n 237, pp. 613-650.

LLORENS ORTUÑO, S (2001): Libro de privilegios y reales mercedes concedidas a la Muy Noble y Muy Leal Ciudad de Orihuela, Instituto Alicantino de Cultura Juan GilAlbert, Alicante, $355 \mathrm{pp}$.

MILLÁN Y GARCIA-VARELA, J. (1984): Rentistas y campesinos. Desarrollo agrario y tradicionalismo político en el sur del País Valenciano. 1680-1840, Instituto Juan GilAlbert, Alicante, $451 \mathrm{pp}$.

NAVARRO HERNÁNDEZ, A.J. (2001): Creación y consolidación del municipio de Callosa de Segura en tiempos de fueros, Instituto de Cultura Juan Gil-Albert, Alicante, 259 pp.

NIETO FERNÁNDEZ, A (Intr.) (1980): Estatutos de Riegos del Juzgado Privativo de Aguas de Rojales dispuestos por el Dr. Jerónimo Mingot y aprobados por Felipe IV en 1625 y usos y costumbres», Caja Rural Central de Orihuela, Almoradí, 54 pp.

PLA ALBEROLA, P. (1993): «La jurisdicción alfonsina como aliciente para la recolonización del territorio», Revista de Historia Moderna, no 12 pp. 79-139.

ROCA DE TOGORES, J (1832): Memoria sobre los riegos de la huerta de Orihuela, Benito Monfort, Valencia.

ROMERO, J. y PERIS, T. (1992): «Usos, distribució i control de l'aigua», en Geografia General dels Països Catalans, Ed. Enciclopedia Catalana, Barcelona, pp. 186-290. 